\title{
Explorasi dan Identifikasi Hama Penganggu Tanaman Sengon (Paraserianthes falcataria) Di Hutan Kemasyarakatan Kairatu Kabupaten Seram Bagian Barat Propinsi Maluku
}

\author{
Fransina.S.Latumahina.S.Hut.MP \\ Email : fransina.latumahina@yahoo.com \\ Staf Dosen Jurusan Kehutanan Fakultas Pertanian \\ Universitas Pattimura Ambon
}

\subsection{Latar Belakang}

Sengon (Paraserianthes falcataria) merupakan salah satu tanaman yang sekarang menjadi primadona dan banyak diusahakan untuk dikembangkan dalam kawasan hutan tanaman perkebunan maupun kebun milik rakyat (hutan rakyat). Salah satu kelebihan sengon adalah pertumbuhannya yang sangat cepat oleh karena itu tanaman sengon pernah dijuluki sebagai pohon ajaib (Miracle tree) dan bersifat multifungsi, memberikan dampak ganda, baik sebagai tanaman produksi maupun sebagai tanaman konservasi dan reboisasi. Faktor pembatas dalam pengembangan tanaman sengon adalah serangan hama yang dapat menurunkan produksi tanaman Sengon baik secara kuantitas maupun kualitas akibat serangan hama yang dapat mematikan tanaman mulai dari tingkat semai sampai dengan tegakan di lapangan. Oleh karena itu perlindungan tanaman sengon merupakan komponen yang cukup penting dalam pengembangannya. Berdasarkan permasalahan diatas maka perlu diadakan penelitian yang lebih mendetail untuk mengetahui jenis hama dan intensitas kerusakan sera luas serangan yang ditimbulkan pada tanaman Sengon di lokasi hutan kemasyarakatan Kecamatan Kairatu Kabupaten Seram Bagian Barat sehingga langkah - langkah pencegahan dan pengendalian dapat dilakukan sedini mungkin. 


\subsection{Tujuan Penelitian}

Penelitian ini bertujuan untuk mengexplorasi dan mengidentifikasi jenis - jenis hama yang menyerang tanaman Sengon (Paraserianthes falcataria, Nielson) serta menentukan intensitas kerusakan dan luas serangan yang ditimbulkannya.

\section{METODE PENELITIAN}

\section{1. Lokasi Dan Waktu Penelitian}

Penelitian dilaksanakan dalam dua tahap yakni penelitian lapangan di kawasan Hutan Kemasyarakatan Desa Waesamu Kecamatan Kairatu Kabupaten Seram Bagian Barat pada bulan Januari hingga Maret 2016 dan dilanjutkan dengan penelitian laboratorium pada Laboratorium Biologi Dasar Fakultas KIP Universitas Pattimura Ambon pada bulan April 2009 hingga selesai

\subsection{Alat Dan Bahan}

\section{Peralatan}

Peralatan yang diperlukan dalam penelitian ini adalah : teropong, kompas, lup (kaca pembesar), mikroskop, kamera, kantong plastik, pisau, tali arafia, parang, botol, karet gelang, dan alat tulis-menulis, kapas, amplop, altimeter, thermometer, hekter, pinset.

\section{Bahan}

Yang menjadi obyek pengamatan dalam penelitian ini adalah hama - hama pada tanaman Sengon dengan bahan penelitian adalah : alkohol $70 \%$.

\subsection{Metode Penelitian}

Penelitian ini menggunakan metode survei, dengan cara pengambilan sampel pada areal seluas $2 \mathrm{Ha}$, dimana terdapat 530 tanaman dan dari tanaman ini diambil sampel sebesar $20 \%$ sehingga total 
pohon sampel adalah 106 pohon sampel. P engamatan pohon sampel dilakukan terhadap daun, dengan menggunakan sistem arah mata angin (utara, barat, timur, selatan) pada tiap tingkatan tajuk (Atas, tengah dan bawah ). Sedangkan untuk hama yang menimbulkan kerusakan pada akar dan batang maka pengamatan dilakukan terhadap batang dan akar.

\subsection{Pelaksanaan Penelitian}

Penelitian ini dilaksanakan dalam dua tahap yaitu penelitian lapangan dan penelitian laboratorium.

\subsubsection{Penelitian Lapangan}

Penelitian lapangan dilaksanakan dengan menggunakan metode pengumpulan data untuk mendapatkan data primer dan data sekunder. Data primer diperoleh dengan melaksanakan penelitian langsung ke lapangan untuk melihat hama dan intensitas kerusakan yang ditimbulkan serta sistem kultur teknis pada areal pertanaman antara lain sanitasi, pemupukan dan tindakan pengendalian hama. Data sekunder meliputi keadaan curah hujan, suhu, kelembaban dan intensitas cahaya yang diperoleh dari stasiun meteorologi setempat.

Untuk memudahkan dalam pengolahan data, maka setiap tanaman terlebih dahulu ditentukan intensitas serangannya berdasarkan keadaan tajuk tanaman, tingkat serangan dan nilai/skor (Mardji, 1996) sebagai berikut:

Tabel 1. Cara menentukan intensitas serangan hama pada setiap tanaman.

\begin{tabular}{|l|l|c|}
\hline \multicolumn{1}{|c|}{ Keadaan tajuk tanaman } & Tingkat serangan & Nilai/Skor \\
\hline Sehat & Sehat & 0 \\
Tajuk terserang/mati $1-24 \%$ & Ringan & 1 \\
Tajuk terserang/mati $25-49 \%$ & Sedang & 2 \\
Tajuk terserang/mati $50-74 \%$ & Berat & 3 \\
Tajuk terserang/mati $75-100 \%$ & Sangat berat & 4 \\
Tajuk dan batang tanaman mati & Mati & 5 \\
\hline
\end{tabular}


Hasil pengamatan yang diperoleh di lapangan kemudian diolah dan dilakukan perhitungan menggunakan pendekatan dari James, 1974 :

- Frekuensi serangan hama :

Jumlah tanaman yang terserang

Frekuensi Serangan

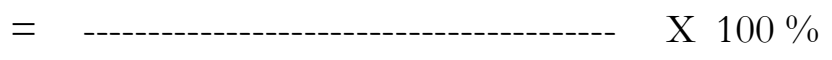

Jumlah tanaman yang diamati

- Intensitas serangan hama Sing dan Mistra (1992) dalam Mardji (1996)

$\begin{array}{llll} & & & \\ \mathrm{I} & = & \mathrm{X}_{1} \mathrm{Y}_{1}+\mathrm{X}_{2} \mathrm{Y}_{2}+\mathrm{X}_{3} \mathrm{Y}_{3}+\mathrm{X}_{4} \mathrm{Y}_{4}+\mathrm{X}_{5} \mathrm{Y}_{5} & \\ \mathrm{I} & = & \text { Intensitas serangan } & \\ \mathrm{X} & = & \text { Jumlah seluruh tanaman } & \\ \mathrm{X}_{1} & = & \text { Jumlah tanaman yang terserang ringan (skor 1) } \\ \mathrm{X}_{2} & = & \text { Jumlah tanaman yang terserang sedang (skor 2) } \\ \mathrm{X}_{3} & = & \text { Jumlah tanaman yang terserang berat (skor 3) } \\ \mathrm{X}_{4} & = & \text { Jumlah tanaman yang terserang sangat berat (skor 4) } \\ \mathrm{X}_{5} & = & \text { Jumlah tanaman yang mati (skor 5) } \\ \mathrm{X}_{1}-\mathrm{Y}_{5} & = & \text { Skor untuk semua tanaman yang terserang ringan sampai mati }\end{array}$

Setelah diperoleh nilai intensitas serangan hama maka selanjutnya ditentukan tingkat serangan pada areal hutan yang diamati untuk mengetahui seberapa berat serangan hama pada waktu pengamatan yang dilakukan seperti disajikan pada Tabel 2 
Tabel 2. Cara menentukan tingkat kerusakan akibat serangan hama.

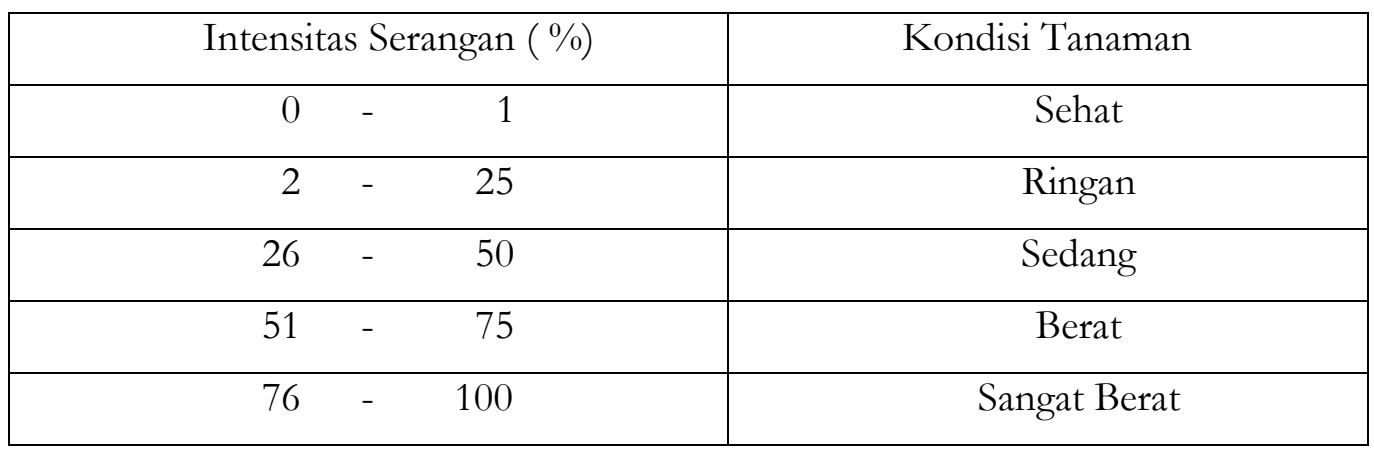

Untuk menghitung luas serangan akibat serangan setiap jenis hama tersebut maka digunakan rumus luas serangan yang dikemukakan oleh Natawigena (1982) :

$$
\mathrm{P}=-\mathrm{a} 100 \%
$$

$\mathrm{b}$

Dimana: P : Luas serangan

a : Banyaknya tanaman contoh yang diserang

b : Banyaknya tanaman contoh yang diamati

\subsubsection{Penelitian Laboratorium}

Penelitian laboratorium dilakukan untuk mengidentifikasi jenis hama yang ditemukan hingga tingkat spesies dengan menggunakan kunci determinasi serangga menurut Borror, dke (1992) serta Achmad Sultoni dan Kalshoven (1981).

\section{HASIL DAN PEMBAHASAN}

\subsection{Kehadiran Jenis Hama}

Berdasarkan hasil penelitian lapangan dan hasil identifikasi laboratorium maka jenis hama yang menyerang tanaman Sengon laut (Paraserianthes falcarataria Nielson) dalam kawasan hutan kemasyarakatan adalah rayap tanah ( Mactotermes gilvus hagen), kupu-kupu kuning (Eurema spp) dan boktor (Xystrocera festiva). 
Hama Boktor (Xystrocera festiva) termasuk ordo coleoptera family cerambyceae. Pada saat penelitian ditemukan bekas gerekan yang menyebabkan luka pada batang. Pada celah batang ditemukan telur boktor yang sudah berlubang - lubang karena telur sudah menetas. Sejak larva keluar dari telur yang baru beberapa saat menetas, larva sudah merasa lapar dan segera melakukan aktivitas penggerekan ke dalam jaringan kulit batang di sekitar lokasi dimana larva berada. Bahan makanan yang disukai larva boktor adalah bagian permukaan kayu gubal (Xylem) dan bagian permukaan kulit bagian dalam (Floem). Adanya serbuk gerek halus yang menempel pada

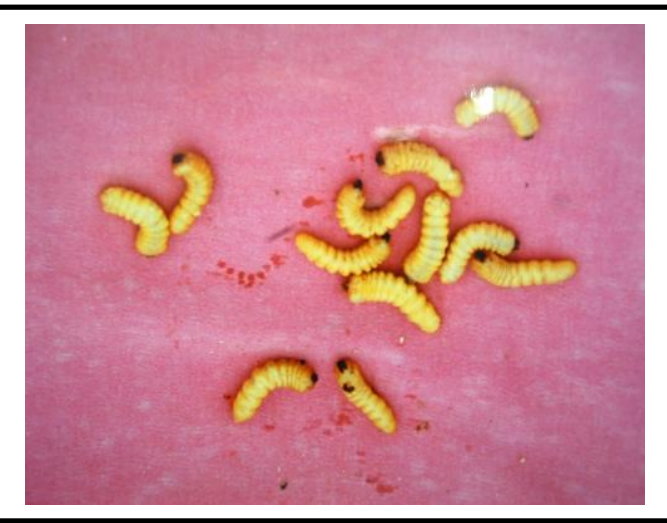

\section{Gambar 1. Ulat Boktor}

permukaan kulit batang merupakan petunjuk terjadinya gejala serangan awal.

Kupu kuning (Eurema blanda) termasuk Famili Pieridae dan ordo Lepidoptera, seluruh tubuhnya berwarna kuning, pada pinggir-pinggir sayapnya terdapat warna hitam. Kupu kuning aktif pada siang hari dan meletakkan telurnya pada permukaan atas daun sengon yang

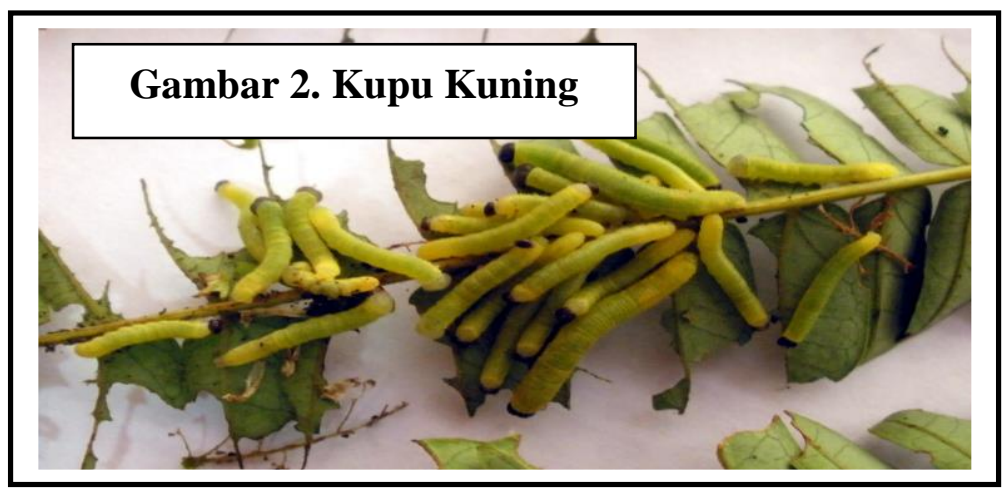
diletakkan. secara berkelompok. Pada saat penelitian ditemukan larva yang baru keluar dari telur (instar 1). Larva yang ditemukan terlihat memakan daun muda sengon hingga gundul dalam waktu yang sangat singkat sedangkan instar pupa tidak ditemukan. Biasanya pupa yang baru terbentuk berwarna hijau kehitaman dan lama kelamaan berubah warna menjadi kuning (Husaeni, 2002). 
Gejala serangan rayap tanah (Mactotermes gilvus Hagen) pada tegakan Sengon dalam kawasan mempunyai ciri khas karena mudah dilihat pada permukaan batang. Pada saat

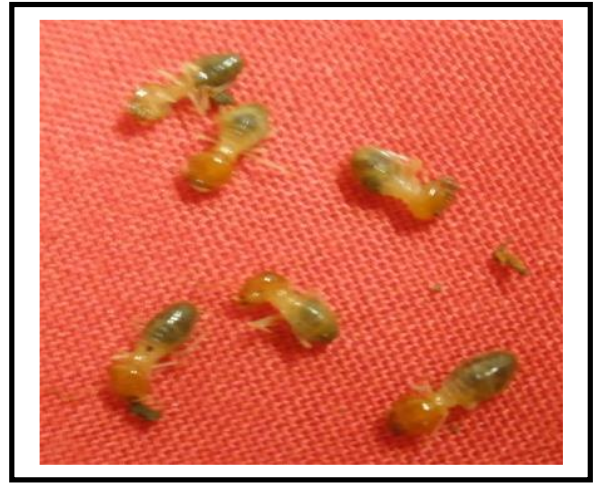

penelitian terlihat adanya penumpukan tanah yang dimulai dari pangkal batang sampai ketinggian $0,5 \mathrm{~m}$ sampai $4 \mathrm{~m}$.

Jumlah telur Macrotermes dapat mencapai \pm 36.000 sehari yang berupa butiran-butiran lepas dan berkelompok dengan panjang badan laron mencapai $2 \mathrm{~cm}$ dengan panjang sayap $9 \mathrm{~cm}$.

\section{Gambar 3. Mactotermes gilvus Hagen}

Apabila tanaman

dibongkar maka akan tampak jelas serangan rayap dimulai dari akar, pangkal batang terus ke batang. Lapisan tanah yang ada di permukaan batang merupakan saluran penghubung dengan sarangnya yang jauh di dalam tanah. Di dalam lapisan tanah ditemukan ditemukan rayap prajurit dan pekerja, rayap pekerja inilah

yang melakukan penggerekan pada batang. Rayap jenis ini akan memakan semua bahan berselulosa pada pohon.

\subsection{Intensitas Kerusakan Tanaman Dan Luas Serangan}

Intensitas kerusakan pada tanaman Sengon laut (Paraserianthes falcarataria Nielson) akibat serangan ketiga jenis hama masing - masing rayap tanah, boktor dan kupu kuning dapat di lihat pada tabel 3 dibawah ini. 


\section{Tabel 3. Intensitas Serangan Dan Luas Serangan pada tanaman Sengon laut (Paraserianthes falcarataria Nielson) Akibat Serangan Rayap, Boktor Dan Kupu Kuning ( \% )}

\begin{tabular}{|c|c|c|c|c|}
\hline \multirow{2}{*}{ Jenis Hama } & $\begin{array}{c}\text { Intensitas } \\
\text { serangan } \\
(\mathbf{\%})\end{array}$ & $\begin{array}{c}\text { Kriteria } \\
\text { Serangan }\end{array}$ & $\begin{array}{c}\text { Luas } \\
\text { Serangan } \\
\mathbf{( \% )}\end{array}$ & $\begin{array}{c}\text { Kriteria } \\
\text { Serangan }\end{array}$ \\
\hline Rayap Tanah & 30,4 & Sedang & 26,2 & Sedang \\
\hline Boktor & 10,2 & Ringan & 4,9 & Ringan \\
\hline Kupu Kuning & 7,8 & Ringan & 3,2 & Ringan \\
\hline
\end{tabular}

Perbedaan intensitas kerusakan dan luas serangan akibat serangan ketiga jenis hama dalam kawasan hutan kemasyarakatan dipengaruhi oleh beberapa faktor yakni :

\section{a. Kultur Teknis}

Tindakan pemeliharaan tanaman yang meliputi pemupukan, pengendalian hama dan penyakit, serta penyiangan terhadap gulma atau tanaman-tanaman penggangu lainnya tidak pernah dilakukan dalam kawasan hutan akibatnya ketahanan tanaman menurun ketika diserang oleh hama. Disamping itu karena tidak pernah dilakukannya tindakan pengendalian hama maka berakibat penyebaran hama semakin meluas sehingga banyak tanaman yang terserang meskipun maish berada dalam kategori ringan. Penyiangan terhadap gulma tidak pernah dilakukan sehingga terjadi kompetisi antara gulma dan tanaman dalam hal unsur hara, CO2 dan air akibatnya pertumbuhan tanaman mengalami gangguan sehingga mudah sekali terserang hama..

\section{b. Iklim}

Faktor iklim yang meliputi suhu,kelembaban dan kecepatan angin turut menunjang pertumbuhan tanaman maupun perkembangan hama. Setiap jenis hama memiliki interval suhu masing-masing untuk hidup dan berkembang biak. Suhu yang efektif bagi 
perkembangan hama yakni suhu minimum $15^{\circ} \mathrm{C}$, suhu optimum $25^{\circ} \mathrm{C}-26^{\circ} \mathrm{C}$, suhu maksimum $45^{\circ} \mathrm{C}$ (Natawigena,1990). Luas serangan rayap tanah lebih tinggi jika dibandingkan dengan luas serangan hama lainnya. Hal inididuga karena ketersediaan bahan makanan dan kondisi lingkungan yang cocok bagi perkembangan rayap serta pengaruh faktor - faktor iklim yang turut mendukung.

\section{c. Tanaman Jenis Lain Sebagai Tanaman Inang}

Beberapa jenis tanaman hutan lain yang tumbuh dalam hutan diduga dapat berperan sebagai tanaman inang bagi ketiga jenis hama yang menyerang Sengon yakni : Jambu Mete (Anacardium ocidentale), Ketapang (Terminalia catapa), Akasia (Acaccia decurens), Lamtoro (Leucaena glauca) dan Nani (Metrosideros vera). Kehadiran tanaman-tanaman hutan ini diduga dapat berfungsi sebagai inang lain atau sumber makanan lain bagi keberadaan dan penyebaran ketiga jenis hama dalam kawasan.

\section{KESIMPULAN DAN SARAN}

\subsection{Kesimpulan}

Berdasarkan hasil penelitian dan pembahasan maka dapat diambil kesimpulan yakni :

1. Hama yang menyebabkan kerusakan pada Sengon laut (Paraserianthes. falcarataria Nielson) di areal Hutan kemasyarakatan Kairatu adalah penggerek batang yakni rayap (Mactotermes giluus Hagen) dan hama pemakan daun yakni hama Boktor (Xystrocera festiva) dan Kupu Kuning ( Eurema spp)

2. Intensitas kerusakan tertinggi pada tanaman sengon laut laut ( $P$. falcarataria Nielson) disebabkan oleh serangan hama rayap sebesar 30,4 \% yang tergolong kriteria sedang, diikuti oleh boktor sebesar 10,2 \% tergolong kriteria ringan dan Kupu Kuning sebesar 7,8 \% yang tergolong kriteria ringan

3. Luas serangan tertinggi pada tanaman sengon laut laut (P. falcarataria Nielson) disebabkan oleh serangan hama rayap sebesar 26,2 \% yang tergolong kriteria sedang, 
diikuti oleh boktor sebesar 4,9 \% tergolong kriteria ringan dan Kupu Kuning sebesar $3,2 \%$ yang tergolong kriteria ringan

\subsection{Saran - Saran}

Beberapa saran yang dapat dikemukakan dari penelitian ini adalah :

1. Untuk mencegah semakin meluasnya serangan perlu dilakukan tindakan pengendalian, dan kultur teknis seperti penyiangan gulma di sekitar pangkal batang batang tanaman, guna mengurangi kelembaban mikro dan kompetisi dengan tanaman tersebut dan pemupukan.

2. Penelitian lanjutan masih diperlukan untuk mengetahui insektisida sistemik yang efektif guna pengendalian hama agar fungsinya sebagai tanaman pengijauan guna pelestarian alam dapat diwujudkan sebaik-baiknya.

3. Perlu diadakan penelitian lanjutan mengenai hama-hama lain yang dapat menyerang tanaman Sengon laut (P. falcarataria Nielson) dalam kawasan pada musim lainnya. 


\section{DAFTAR PUSTAKA}

Anonimous, 1976. Vademecum Kehutanan Indonesia. Departemen Pertanian Direkrorat jendral Kehutanan. Jakarta

Anonimous, 1990. Teknik Pembuatan Tanaman. Departemen Kehutanan Direktorat Jendral Reboisasi Dan Rehabilitasi Lahan. Direktorat Hutan Tanaamn Industri.

Atmosuseno. S. 1995. Kayu Komersial. Penerbit Penebus Swadaya

Boror. Triplehorn. Johnson, 1992. Pengenalan Pelajaran Serangga Edisi Keenam. Gadjah Mada University Press

Setiawan. I., 1996 Penghijauan Lahan Kritis. Penerbit Penebar Swadaya. Surabaya

Suratomo. F.G., 1976. Ilmu Perlindungan Hutan. Proyek Peningkatan Mutu Perguruan Tinggi Institut Pertanian Bogor.

Sunjaya. P.I 1970. Dasar-dasar Ekologi Serangga. 